\title{
Literatura e Arte sobre o Cuidar em Neurologia
}

\author{
Literature and Art of caring in Neurology
}

\author{
Marco Orsini ${ }^{1}$, Carlos Henrique Melo Reis', Acary Bulle Oliveira ${ }^{3}$, Marco Antônio \\ Araújo Leite ${ }^{4}$, Antônio Catharino ${ }^{5}$,Valéria Silveira 6 , Marcos RG de Freitas ${ }^{7}$, Sara \\ Lúcia Silveira de Menezes ${ }^{8}$, Clynton Lourenço Correa ${ }^{9}$, Marco Trocoli Chieia ${ }^{10}$, \\ Fábio Henrique Porto ${ }^{11}$, Ronaldo Luiz'
}

\section{RESUMO}

As pessoas são diferentes, entretanto a dignidade é a mesma. A arte de cuidar assim como as verdadeiras obras-primas não muda nem envelhece, pelo contrário, torna-se fortificada e incandescente diante da atual e asfixiada relação entre os personagens, médico-paciente. Objetivo. Promover, diante de relatos históricos, uma discussão provocativa acerca da arte de cuidar em neurologia, que com o passar do tempo tornou-se turbilhonada e diluída diante de interesses vários e, principalmente da miséria nas relaçóes humanas. Método. Revisão da literatura com artigos das bases Medline, SciELO, Cochrane e Lilacs, de 1939-2011. Discussáo. Acredita-se que as diretrizes curriculares para o ensino médico no Brasil devem estimular práticas que promovam um olhar e atitude mais humanizada, mais próximas das necessidades da população. Em se tratando da neurologia faz-se necessário que tais ações proporcionem, de igual modo, mudanças e a criação de um modelo relacionado à abordagem e atitudes frente aos pacientes. Conclusáo. Relatos históricos, expressados na arte e na pintura, enalteceram o cuidar médico. Em vista disso, estratégias que possibilitem melhoria do contato humano entre médico-paciente devem estimular a criação de um arcabouço alicerçado em espaços de comunicação permanentes e um completo entendimento sobre os problemas e fragilidade dos que padecem.

Unitermos. Neurologia, Assistência Centrada no Paciente, Humanismo.

Citaçáo. Orsini M, Reis CHM, Oliveira AB, Leite MAA, Catharino A, Silveira V, de Freitas MRG, Menezes SLS, Correa CL, Chieia MT, Porto FH, Luiz R. Literatura e Arte sobre o Cuidar em Neurologia.

\section{ABSTRACT}

People are different, but the dignity is the same. The art of caring, as well as truly masterpieces, not change nor age, however, it is fortified and given the current incandescent and stifled relationship between the characters relationship, doctor-patient. Objective. To promote, in the face of historical accounts, a discussion about the art of care in neurology, that over time became turbulent and diluted before many interests, and especially extreme poverty in human relationships. Method. This literature review used articles from Medline, SciELO, Lilacs and Cochrane between the years 1939 to 2011. Discussion. We believe that the curriculum guidelines for medical education in Brazil should encourage practices that promote a more human attitude and look, closer to the needs of the population. In the case of neurology it is necessary that such actions provide, similarly, changes and the creation of a model related to the approach and attitudes towards patients. Conclusion. Many historical accounts, as expressed in art and painting, praised the medical care. As a result, strategies that facilitate improvement of human contact between doctor and patient should encourage the creation of a framework grounded in permanent communication spaces and a full understanding of these problems.

Keywords. Neurology, Patient-Centered Care, Humanism.

Citation. Orsini M, Reis CHM, Oliveira AB, Leite MAA, Catharino A, Silveira V, de Freitas MRG, Menezes SLS, Correa CL, Chieia MT, Porto FH, Luiz R. Literature and Art of caring in Neurology.

Trabalho realizado no Serviço de Neurologia - Hospital Universitário Antônio Pedro - Universidade Federal Fluminense - UFF, Rio de Janeiro-RJ, Brasil.

1.Graduando e Interno de Medicina, Doutor em Neurologia - HUAP Serviço de Neurologia - UFF, Pesquisador do Hospital Geral de Nova Iguaçú - HGNI, Pesquisador do Programa de Mestrado em Ciências da Motricidade - Centro Universitário Augusto Motta, UNISUAM, Bonsucesso-RJ, Brasil; 2.Neurologista, Mestre, Professor do Hospital Geral da Posse - Nova Iguaçu-RJ, Brasil; 3.Neurologista, Doutor, Professor Afiliado do Departamento de Neurologia e Neurocirurgia da Universidade Federal de São Paulo, São Paulo-SP, Brasil; 4.Neurologista, Doutor, Professor Adjunto de Neurologia - Serviço de Neurologia - HUAP - UFF, Niterói-RJ, Brasil; 5.Neurologista, Mestre, Professor do Hospital Geral da Posse - Nova Iguaçu-RJ, Brasil; 6.Neurologista, Mestre, Professor do Hospital Geral da Posse - Nova IguaçuRJ, Brasil; 7.Neurologista, Doutor, Professor Titular e Chefe do Serviço de Neurologia - HUAP- UFF, Niterói-RJ, Brasil; 8.Fisioterapeuta, Programa de Mestrado em Ciências da Reabilitaçăo, Centro Universitário Augusto Motta - UNISUAM, Bonsucesso-RJ, Brasil; 9.Fisioterapeuta, Doutor em Ciências Morfológicas - UFRJ, Professor Adjunto do Curso de Fisioterapia - UFRJ, Rio de Janeiro-RJ, Brasil; 10.Neurologista, Universidade Federal de São Paulo, UNIFESP, Sáo Paulo-SP, Brasil; 11.Neurologista, Especialista em Neurologia Cognitiva - Universidade de São Paulo - USP, São Paulo-SP, Brasil; 12.Médico, Departamento de Clinica Médica Unigranrio - Duque de Caxias-RJ, Brasil.

Endereço para correspondência: Marco Orsini

Rua. Herotides de Oliveira, n2 complemento 801 - Jardim Icaraí CEP 24230-230, Niterói-RJ, Brasil. E-mail: orsinimarco@hotmail.com 


\section{INTRODUÇÃO}

Acredita-se que existam palavras favoritas e clássicas no âmbito da neurologia, palavras que enriquecem, engrandecem e fortalecem quem as verbaliza e que, logicamente, não podem faltar em sessões clínicas. Uma das principais é a palavra deficiência, significado de comprometimento, dificuldade ou deterioração. Terminologia utilizada para definir a ausência ou a disfunção de estruturas psíquicas, fisiológicas ou anatômicas. O leitor provavelmente se perguntará, como não citá-las? A grande questão gira em torno do momento oportuno de citação. Muitas vezes o profissional de saúde se depara com pacientes fragilizados fisicamente e emocionalmente e é instintivamente taxativo ao caracterizar e identificar o problema. Tal termo leva consigo uma avassaladora carga negativa e depressiativa do indivíduo, fato que ao longo dos anos torna-se cada vez mais rejeitado pelos especialistas da área e, em especial, pelos próprios portadores. Sabe-se que as discussões devem ser dotadas de conceitos e terminologias que não podem ser descartados - atentase somente que sejam utilizados com sensibilidade.

Nesse contexto acredita-se que a Educação Médica atingiu um marco em que deve se preocupar na formação de profissionais detentores não somente de técnica impecável, como também cuidadores humanizados, sensíveis, preparados para lidar consigo e principalmente com seus pacientes, tarefa que exige trabalhar com os mais diversos valores inseridos em complexos contextos históricos, culturais e sociais. Em vista disso, faz-se necessária uma rediscussão sobre a inserção da arte e uma reformulação nos novos projetos políticos pedagógicos dos cursos de medicina. Ser um bom médico certamente não depende exclusivamente da quantidade e da qualidade da tecnologia incorporada à prática. A medicina é uma profissão muito antiga e sempre existiram bons médicos ${ }^{1,2}$.

Segundo Tapajós R (2002) ${ }^{3}$, este tipo de conhecimento, produzido pelas Humanidades, é singular e não científico em essência. É diverso daqueles conhecimentos científicos com que educadores e discentes estão acostumados a trabalhar nos currículos médicos. Sendo diverso, requer abordagens curriculares diferenciadas. Em se tratando de neurologia, tal proposta segue a mesma linha de raciocínio - ensinar|fornecer conhecimento, visando expor cada vez menos o enfermo.
A tarefa do presente material é a formação de um arcabouço reflexivo baseado em citaçôes literárias e artísticas sobre o ato de cuidar, além de aclamar para um enaltecimento de seu valor, com objetivo de facilitar a execuçâo de objetivos no âmbito da neurologia.

\section{MÉTODO}

Esta revisão da literatura utilizou artigos das bases de dados Medline, SciELO, Cochrane e Lilacs compreendidos, entre os anos de 1939 - 2011. Foram encontrados sessenta e sete artigos e materiais diretamente relacionados ao tema. Utilizaram-se as seguintes palavras-chave: Neurologia, Assistência Centrada no Paciente, Humanismo em português; como também suas similares em inglês. Utilizou-se para a pesquisa principalmente artigos de atualização que apresentavam a neurologia e o cuidar como foco principal das discussōes. O material não utilizado fora descartado por conta da falta de especificidade com o tema em questão.

\section{Doenças Neurológicas Representadas na Literatura e nas Artes}

Existem doenças e condiçôes patológicas várias representadas na Literatura e nas Artes. As doenças degenerativas e transtornos psiquiátricos são alguns exemplos de representaçóes bastante prevalentes na neurologia.

Em uma dessas obras, intitulada "Triste Herencia (1899)", o autor descreve inúmeras crianças em uma praia do mediterrâneo, todas descarnadas nos membros inferiores, algumas de encontro a uma "figura religiosa", outras ao fundo sem esperança, possível sequela da poliomielite. O sentimento se não visto, pode ser sentido (Figura 1).

Outros, entretanto, consideram que tal expressão, em épocas passadas, era taxativa para referir-se às deficiências apresentadas por crianças como consequência de enfermidades de seus progenitores, consideradas vergonhosas por ser fruto de um estilo de vida pecaminoso ou diferente dos padróes considerados normais pela sociedade. Sífilis, Tuberculose, Alcoolismo eram marcantes. Muitas desses crianças passaram a "sobreviver" de caridades exercidas por instituiçóes públicas, privadas e sobretudo da igreja. A exclusão mostra-se presente sob essa ótica de reflexão ${ }^{2}$. 


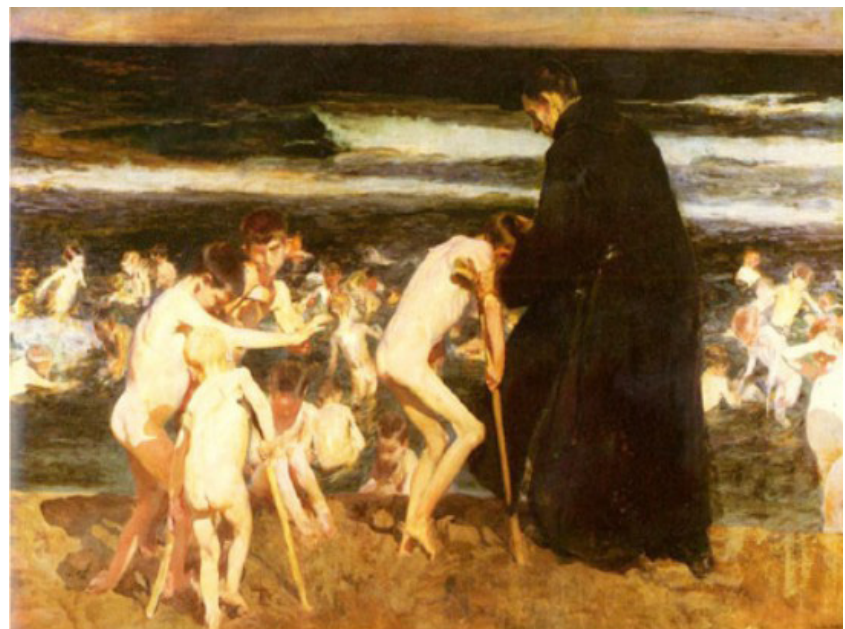

Figura 1. Triste Herencia (1899) - Joaquin Sorolla y Bastida http://www.joaquin-sorolla-y-bastida.org/Triste-herencia-(Sad-Inheritance).html (Mterial de Dominio público)

O simbolismo e romantismo representados nelas, além de seu contexto histórico-social também é relevante aos que prestam cuidados e torna-se ainda mais relevante para os profissionais que lidam com neurologia, na medida em que toca também em outros campos de conhecimento que têm seus próprios arcabouços intelectuais e teóricos, como, por exemplo, a Filosofia, a Sociologia e a Antropologia.

Infelizmente, inúmeros autores consideram que na atualidade os esforços de ensino em currículos médicos tradicionais parecem devotar-se unicamente à Biologia e à Epidemiologia das patologias. Sabemos que tal estratégia é mandatória e primordial para um real conhecimento técnico e científico de tais injurias, entretanto uma unificação com a literatura|artes iria engrandece-los ${ }^{3}$.

Compartilhamos com mesma linha de raciocínio e adicionamos que a inserção dessas disciplinas serviria para aflorar determinados sentimentos nos que prestam cuidados. A reflexão sobre crenças, capacidade de autopercepção e percepçáo do outro, busca de diferentes comportamentos em situaçóes de estresse psíquico e principalmente das potencialidades humanas e capacidade de lidar com adversidades.

Dentre todas essas questóes, o "entendimento dos valores", que faz de pessoas juntas uma comunidade, é certamente a maior vertente para aprendermos a lidar com o que significa ser humano e viver uma vida humana ${ }^{4}$.

\section{O marinheiro sifilítico descrito por Hélio Pelegrino:} Palavras que ferem...

$\mathrm{O}$ ainda estudante de medicina Hélio Pellegrino recebera uma carta de Carlos Drummond de Andrade no dia 09 de dezembro de 1947 com o seguinte dizer: "Não sei se você será um médico razoável, mas estou certo de que o seu instinto poético, tão profundo, saberá fazer da medicina uma coisa bela"5.

A aproximaçáo de Pellegrino com a filosofia o fez refletir à respeito de inúmeros episódios vivenciados em uma enfermaria, dentre eles do velho marinheiro. As palavras proferidas pelos apresentadores passaram a inquietá-lo e descobrir a essência das relaçóes humanas. Hélio descreve uma aula com requintes literários:

"O doente, com Tabes Dorsal, ao centro do anfiteatro escolar, era um velinho miúdo, ex-marinheiro, vestido com o uniforme de onde estava internado. Jamais me sairá da memória o antigo lobo do mar, exilado das vastidóes marítimas, feito coisa, diante de nós. Suas andanças pelo mundo, seus amores em cada porto ficavam reduzidos, em termos de anamnese, a uma contágio venéreo ocorrido décadas atrás. O velinho, contrafeito, engrolado o seu depoimento, fustigado pelos gritos de "fala mais alto!", com que buscávamos saciar nosso zelo científico. De repente, o desartre. Sem controle esfincteriano, o velho urinou-se na roupa, em pleno centro do mundo. Vejo-o curvado para frente, tentando esconder com as mãos a umidade untrajante. Seu pudor, entretanto, nada tinha a ver com a ciência neurológica. Esta lavrara um tento de gala e o sintoma foi saudado com ruidosa alegria, como um gol decisivo na partida que ali se travava contra a sífilis nervosa. $\mathrm{O}$ velho ficou esquecido como um atropelado na noite. A aula prosseguiu, brilhantemente ilustrada. Os reflexos e a sensibilidade cutânea do paciente foram pesquisados com maestria. Agulhas e martelos tocavam sua carne- essa carne revertida de infinita dignidade, que um dia ressurgirá na hora do juízo. Meu colega percebeu comigo o acontecimento espantoso: “ O marinheiro está chorando" - me disse. Fomos três a chorar ${ }^{5}$. A decepção foi intensa e imensa.

Podemos transferir as consideraçóes supracitadas para a problemática vivenciada na atualidade. Porquanto, devemos procurar respaldar o cuidado e a arte através 
principalmente do respeito ao ser humano na sua dimensionalidade moral, ética, ambiental, cultural, política e econômica. Ao falarmos em moral, estamos buscando a adesão de um consenso para partilha de sentimentos que envolvam o cotidiano do cuidar, revestindo-se de poder de criação - "Arte", e que chamamos de "ética de sentimentos"'.

\section{O Zelar e o reconhecimento Médico pintado por Frida Kahlo}

Felizmente também existem passagens na pintura e na literatura que engrandecem o zelar médico.

Em 1913, com seis anos, Magdalena Carmen Frida Kahlo contrai o vírus da pólio e desenvolve a poliomielite anterior aguda, doença do neurônio motor inferior que lhe promove um comprometimento da função motora no seu pé direito. A partir daí a pintora mexicana começa a utilizar calças e depois, longas e exóticas saias, que vieram a ser uma de suas marcas pessoais, podendo ser vistas em muitas fotografias e quadros da época, como o na Figura 2. Infelizmente não existem relatos na literatura sobre os cuidados recebidos por Frida Kahlo durante o episódio da poliomielite anterior aguda. Nem ao certo sabemos se fora assistida por um neurologista.

Vitimada por um terrível acidente que a aprisionou sob um colete de gesso por toda a vida, a dor de Frida foi retratada na sua pintura de forma a marcar a sua obra. Os auto-retratos e as representaçôes de cenas do hospital

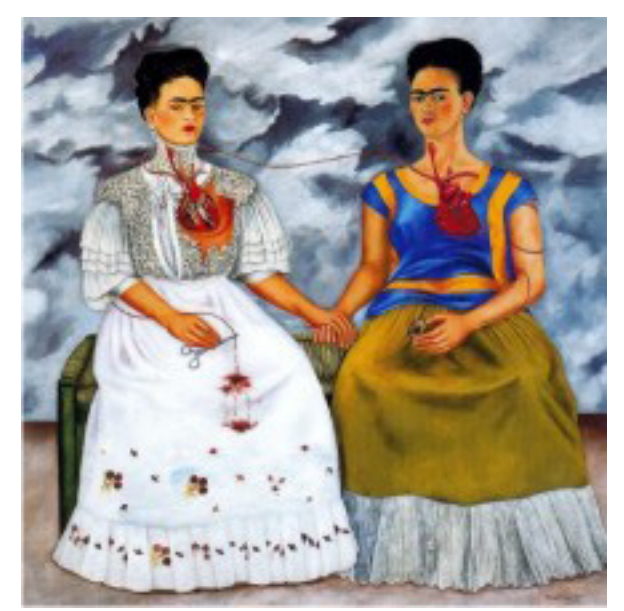

Figura 2. (Frida Kahlo - Le Due Frida/The Two Fridas - 1939). http://connect.in.com/frida-kahlo-paintings/images-le-due-fridapainting-by-frida-kahlo-2-561158173517.html (Material de Domínio Público) ou de procedimentos médicos foram retratados de forma a fazer o observador partilhar da sua dor. Retratou a lápis a cena do acidente, sem respeito por regras ou perspectivas. Nesse episódio entretanto, enaltece o cuidar médico realizado pelo Dr. Juan Farril ${ }^{7}$.

A pintora destaca a participação do médico com o seguinte trecho: "Estive doente durante um ano: 19501951. Sete operaçôes na coluna. O Dr. Farril salvou-me. Restitui-me a alegria de viver. Ainda estou em uma cadeira de rodas e ainda não sei quando poderei voltar a andar de novo. Tenho um colete de gesso que, em vez de horrivelmente maçador, me ajuda a suportar melhor a coluna. Não sinto dores, só um grande cansaço... e, como é natural, por vezes desespero. Um desespero indescritível. No entanto quero viver. Já comecei com um pequeno quadro que vou dar ao Dr. Farril e que estou fazendo com todo o meu carinho por ele" - Figura 3. Acreditamos que a relação da pintora com o Dr. Farril perpassou o simples ato de cuidar. Refletimos sobre um possível encontro da razão com a emoção, da objetividade com a subjetividade, no intento da construção de saberes e de uma ciência mais pessoalizada e humana.

Apesar da evolução e avanço dos conhecimentos atuais, certamente a medicina não pode ser considerada uma ciência exclusivamente exata (mesmo que alguns queiram isso), tampouco uma ciência eminentemente biológica ${ }^{8}$. Por lidar diretamente com pessoas, a medicina passa também obrigatoriamente pelas ciências humanas.

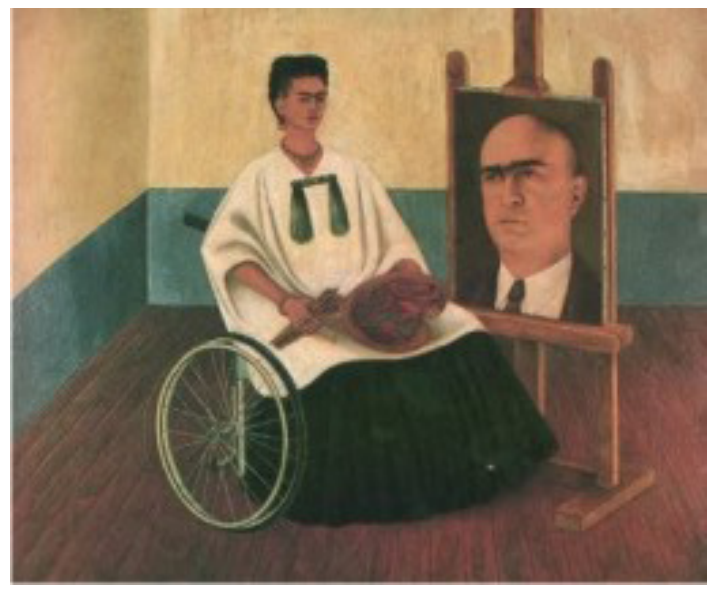

Figura 3. Frida ao lado do Dr. Juan Farril, 1951.

http://www.fridakahlofans.com/c0602.html (Material de Domínio Público) 
Não somente no âmbito da neurologia, entretanto em todas as áreas da medicina, existe uma verdadeira obsessão monetária associada a uma galopante pressão da indústria farmacêutica e tecnológica. Esses fatores contribuíram negativamente na relação médico-paciente. Essa miserável mentalidade jamais poderá abarcar a nobreza da formação médica, o senso de humanidade, a dignidade com o próximo, o cuidado e os aspectos éticos da relação entre os personagens. Como pesquisadores e adeptos da Medicina Baseada em Evidências ressaltamos que não estamos declinando do ponto de vista técnico - científico. Necessitamos, entretanto, de programas de antropologia, filosofia, história da medicina e ética para o fortalecimento de nossas atividades profissionais e melhor contato com os que requerem auxílio.

\section{Franklin Delano Roosevelt e a poliomielite anterior aguda}

Franklin Delano Roosevelt, 32a presidente norteamericano, fora acometido pelo virus da poliomielite aos 39 anos. Nessa época a família passava férias de verão em Campobello, na costa escarpada atlântico-canadense. Passagens literárias apontam que Franklin correu quilômetros antes de mergulhar nas águas gélidas da baía Fundy. Ao anoitecer, começara a apresentar calafrios, febricula e intenso quadro álgico na região dorsal. Após o terceiro dia de início do quadro os membros inferiores já encontravam-se paralisadas com posterior descarnamento. Passados 15 dias um médico especialista de Boston diagnosticou corretamente a pólio (poliomielite anterior aguda). Roosevelt empenhou-se na prática diária de natação para uma tentativa de restabelecimento da função motora. Também fora utilizado um tutor para melhorar a qualidade dos padróes de marcha ${ }^{9}$ - Figura 4 . Os tratamentos de fisioterapia e hidroterapia que fizera melhoraram o seu estado geral mas ele só veio a recuperar alguns movimentos. As ocasióes em que andava por uns poucos metros em comícios eleitorais, dando provas da sua força de vontade, fazia-o através de uma técnica de contorcionismo que desenvolvera, rodando as "ancas", enquanto as pernas eram suportadas pelas órteses metálicas rígidas que tinha dentro das calças.

A doença comprometera os neurônios motores da medula lombossacra ocasionando um comprometimento da força muscular de caráter assimétrico e desproporcional. Frequentemente utilizava cadeira de rodas, mas fez grandes esforços para mascarar tal dificuldade do público externo. De fato, na literatura vigente, só existem duas fotos conhecidas de Roosevelt em cadeira de rodas (Figura 5). Mesmo como Presidente dos Estados Unidos, preferia deambular com a ajuda de um guarda-costas do Serviço Secreto, do que utilizar uma órtese (cadeira de rodas). Entretanto, apareceu dramaticamente de "muletas" para indicar Alfred E. Smith na Convenção Democrata de $1924^{10,11}$. Relatos sobre a qualidade e dedicação dos profissionais de saúde na assistência à Franklin Roosevelt são escassos, entretanto ao que parece, recebeu correta orientaçáo e prescrição de equipamentos de assistência e suporte. Transformou-se num poderoso símbolo da habilidade que um indivíduo pode ter para superar os estragos psíquicos e motores provocados pelo vírus da pólio. Um jovem de aproximadamente 12 anos escrevera a seguinte carta para Roosevelt: "Eu não sei quando é que voltarei a andar, mas não perdi a esperança. O senhor teve paralisia, mas isso não o impediu de progredir”.

\section{Dramatização para estudantes de Neurologia. Faz-se necessária?}

Nos últimos anos, estudos sobre diferentes metodologias de ensino-aprendizagem atrelados à questão da humanização na relação médico-paciente vêm sendo desenvolvidos. Tais estratégias convergem para alguns elementos comuns como, por exemplo, o uso de metodologias ativas, centradas nos participantes, e o trabalho em pequenos grupos, em busca de reflexão e desenvolvimen-

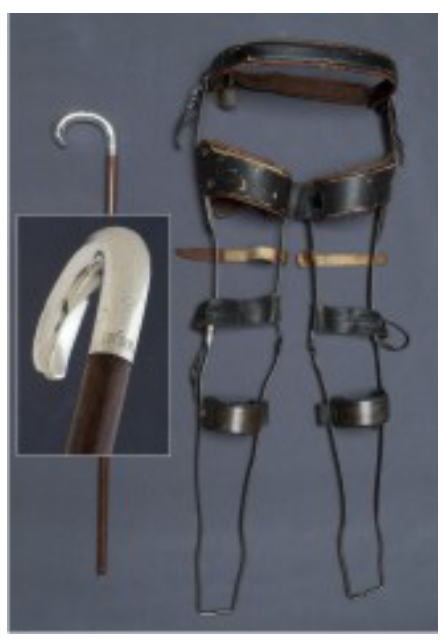

Figura 4. Tutor Utilizado por Fraklin Roosevelt.

http://americanhistory.si.edu/ polio/howpolio/enlargerehab_0 http://www.fridakahlofans. com/c0602.html 9.htm (Material de domínio publico) 


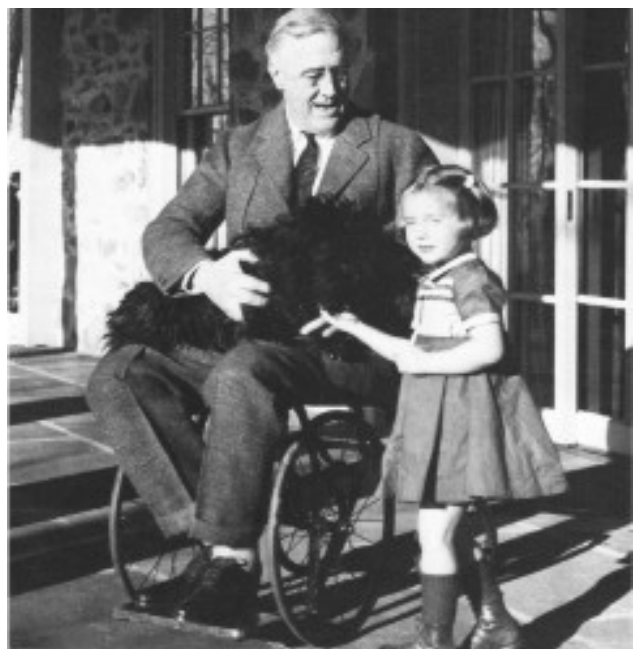

Figura 5. Schlesinger, Arthur M. Jr., The Age of Roosevelt, 3 vols, (1957-1960), the classic narrative history. Strongly supports FDR. Online at vol 2. (Material de Dominio Público)

to de competências para lidar com os diferentes tipos de pacientes e de personalidades. Apesar de tais metodologias de ensino abarcarem toda a formação médica de uma maneira geral, os que lidam com a neurologia especificamente sentem-se muitas vezes fragilizados e vulneráveis quando em contato com problemas de alta complexidade, como, por exemplo, o estabelecimento do diagnóstico ou tratamento paliativo.

Nesse contexto encontra-se a dramatização, um recurso psicodramático que permite a troca de papéis entre todos os envolvidos no processo e pode servir de alicerce para melhorar a relação médico-paciente. Dramatizar pode ser considerado, de maneira espontânea, proporcionar a experimentação dos pontos de vista de outras pessoas, ao interpretar o papel de outrem ${ }^{11}$. Aplicado ao campo da educação médica, visa à percepção objetiva de sentimentos e atitudes frente à prática profissional, sendo utilizado com estudantes e profissionais de diversas especialidades médicas ${ }^{12}$.

A falta de um espaço para a troca de saberes a respeito de experiências vivenciadas com determinados pacientes contribui para acentuar o isolamento, trazendo a crença de que se trata de um problema único que não pode ser compartilhado, pois ninguém mais estaria passando por isso e não o compreenderia ${ }^{12}$.

O fornecimento do diagnóstico em neurologia é outra problemática vivenciada pelos profissionais. Os mesmos devem demonstrar sensibilidade para com o so- frimento do enfermo e da família, promovendo espaços de escuta e diálogo, esclarecendo dúvidas, sendo receptivos e compreensivos diante das reaçóes expressadas nesse momento para que nenhum dos envolvidos no processo perca as esperanças. Tal questáo deve ser exaustivamente trabalhada nos programas de formação desses profissionais.

O momento do diagnóstico, logicamente dependendo da gravidade da injúria apresentada, é um processo de desestruturação inicial, mas que culmina com posterior aceitação e estruturação familiar quando possível ${ }^{13}$. Esta aceitação e adaptação são compreensíveis já que a família vai desenvolver esforços para se adaptar à nova situação aprendendo a acomodar-se à doença e às alteraçôes em sua dinâmica cotidiana.

$\mathrm{O}$ neurologista não deve esquecer que o estigma provocado a um enfermo vitimado por um doença neurológica constitui-se em um problema social que produz efeitos desagradáveis, constrangedores, limitantes. É a sociedade que define a deficiência como uma incapacidade, algo indesejado e com limitaçóes para quem a apresenta, geralmente maiores do que as existentes, já que é ela que define os padróes. Dessa forma, faz com que a pessoa com deficiência sofra as consequências dessa determinação, pelo estigma e pela segregaçáo. Nesse panorama, tal profissional deve ser dotado de extrema sensibilidade e, logicamente, de competência emocional para saber o correto momento de noticiar e a maneira de como agir à reaçóes durante a notícia.

\section{Deficiência da Arte em Cuidar do Neurologista: Ainda existe tempo?}

Para o desenvolvimento dessa parte lembramos do artigo intitulado: "Frida Kahlo: A arte como desafio à deficiência e à dor, com enfoque na poliomielite anterior aguda" ". No material Frida Kahlo, pintora mexicana, representa em suas obras de arte as mutilaçóes físicas que sofreu, ao episódio da poliomielite anterior aguda, junto aos sonhos políticos de uma revolução comunista nas Américas. Nos escritos e desenhos da pintora se inscreve o corpo fragilizado, mutilado, mas a dor é sublimada com humor. Frida tece um elo indestrutível entre vida e obra, com a explícita conexão de tinta e sangue que tingem as páginas de suas anotaçóes ${ }^{14}$. Como nossa sociedade cul- 
tua o corpo útil e aparentemente saudável, os deficientes remetem a fragilidade que se quer negar. Não os aceitamos porque não queremos que eles sejam como nós, pois assim nos igualaríamos. Essa bárbara frase expressa à realidade - o quanto somos cruéis como espécie. $\mathrm{O}$ conceito de enfermidade e criatividade artística requer uma profunda análise, podendo ser encarado como uma forma de exorcismo da dor e do sofrimento dos que sofrem diretamente ou mesmo dos que se consideram impotentes perante a tal situação. Aproveitamos para acrescentar a existência nos dias de hoje, de um verdadeiro "vulcão caótico" nas relações humanas, dentre elas na relação médico-paciente. Relação que parece retroceder num período de total agigantamento tecnológico da Medicina.

A representação artística das deficiências e incapacidades "evoluíram" paralelamente com o sentir dos homens de cada época e de acordo com sua evolução social ${ }^{15}$. Nossos pensamentos podem ser melhor expressados após percepção da gravura Der Arzt (O médico) de Ivo Saliger, realizada em 1920. Nela, o médico posta-se perplexo diante da delicada situação do enfermo. Seus olhos obstinados mostram que luta contra a morte e, para tal, está disposto a tudo, é a arte da medicina. Essa postura deve sempre ser adotada na prática médica diária, principalmente nesse momento de robotização do ser humano. $\mathrm{O}$ novo paradigma dos novos expositores é expressar na Arte a grandiosidade de prestar cuidado e reforçar o quanto é importante à relação médico-paciente nessa trajetória entre a matéria e o indefinido.

\section{CONSIDERAÇÕES FINAIS}

A busca por soluçôes que possibilitem melhorias na relação entre o médico e paciente estimula, assim, a criação e a sustentação de espaços de comunicação permanentes que favorecem a livre expressão, a dignidade, o respeito à diversidade de opinióes e a criatividade. Os neurologistas devem repensar suas atividades no tocante ao acompanhamento dos pacientes vitimados por injúrias neurológicas.

Temos em mente que novas diretrizes curriculares para o ensino médico no Brasil têm fomentado essas discussóes desde o início do curso, em especial as que promovam um olhar mais humanizado e mais próximo das necessidades das populaçóes. É de interesse que essas açóes propiciem, de igual modo, mudanças em relação aos sentimentos e atitudes vivenciados pelos alunos.

Nesse sentido, a literatura e a arte poderiam abrilhantar tal discussão e servirem como alicerce para mudanças no pensar. Além disso, representam a evolução do conhecimento acerca da vida e da própria história da humanidade no Planeta, sendo muito importante para um amplo entendimento do ser humano. Tais ingredientes nos permitem permear pela obscuridade do sentimento humano, exercendo inconscientemente novas descobertas e pensamentos sobre o cuidar.

\section{REFERÊNCIAS}

1.Tapajós R. Introducing the arts into medical curricula. Interface-Comunic, Saude, Educ 2002;6:27-36.

2.Moreno VJ. Locos, enanos, negros y niños palaciegos. Gentes de placer que tuvieron los Austrias en la corte española desde 1563 a 1700. México: Presencia; 1939, 146p.

3.Marshall PA, O’Keefe JP. Medical students' first-person narratives of a patient's story of AIDS. Soc Sci Med 1995;40:67-76.

http://dx.doi.org/10.1016/0277-9536(94)00128-G

4.Wilson HS. A case for humanities in professional nursing education. Nurs. Forum 1974;13:406-17.

http://dx.doi.org/10.1111/j.1744-6198.1974.tb00077.x

5.Pires PR. Hélio Pellegrino: A paixão indignada. Rio de Janeiro. RelumeDumará: Prefeitura 1998 (Perfis do Rio), 122p.

6.Silva LWS, Nazario NO, Silva DS. Arte na enfermagem: iniciando um diálogo reflexivo. Texto Contexto Enferm 2005;14:120-3.

7.Orsini M, De Freitas MRG, Carvalho LB. Frida Kahlo: a arte como desafio à deficiência e à dor, com enfoque na poliomielite anterior aguda. Rev Bras Neurol 2008;44:5-12.

8.Filho VPD, Sá FC. O cuidado na prática médica. O Mundo da Saúde 2009;33:189-94.

9.Schlesinger AM Jr. The Age of Roosevelt. 3 volumes: 1. The crisis of the old order, 1919-1933; 2. The coming of the New Deal; 3. The politics of upheaval. Boston: Houghton Mifflin Co., 1957-1960.

10.Goodfield J. Valor ante la adversidad. Salud Mundial 1995;48(1):24-5.

11.Garrido EM. Psicologia do Encontro. São Paulo: Duas Cidades, 1996, 78p. 12.Ramos-Cerqueira ATA. Era uma vez... contos de fadas e psicodrama auxiliando alunos na conclusão do curso médico. Interface (Botucatu). [online]. 2005;9(16):81-9.

13.Dantas MSA, Collet N, Moura FM, Torquato IMB. Impacto do diagnóstico de paralisia cerebral para a família. Texto Contexto Enferm 2010;19:229-37. http://dx.doi.org/10.1590/S0104-07072010000200003

14.Budrys V. Neurological deficits in the life and works of Frida Kahlo. Eur Neurol 2006;55:4-10.

http://dx.doi.org/10.1159/000091136

15.Cano de la Cuerda R, Collado-Vázquez S. Deficiencia, discapacidad, neurología y arte. Rev Neurol 2010;51:108-116. 